\title{
The relationship between self-efficacy and some demographic and socioeconomic variables among Iranian Medical Sciences students
}

This article was published in the following Dove Press journal:

Advances in Medical Education and Practice

\author{
Seyed Jalil Seyedi-Andi' \\ Fatemeh Bakouei ${ }^{2,3}$ \\ Hajar Adib Rad ${ }^{2,3}$ \\ Soraya Khafri ${ }^{4}$ \\ Asgari Salavati ${ }^{5}$
}

'Social Determinants of Health Research Center, Health Research Institute, Babol University of Medical Sciences, Babol, Islamic Republic of Iran; ${ }^{2}$ Infertility and Reproductive Health Research Center, Health Research Institute, Babol, Islamic Republic of Iran; ${ }^{3}$ Department of Midwifery, School of Medicine, Babol University of Medical Sciences, Babol, Islamic Republic of Iran; ${ }^{4}$ Department of Statistic and Epidemiology, School of Medicine, Babol University of Medical Sciences, Babol, Islamic Republic of Iran; ${ }^{5}$ Department of Psychiatrics, Babol University of Medical Sciences, Babol, Islamic Republic of Iran
Correspondence: Fatemeh Bakouei Infertility and Reproductive Health Research Center, Health Research Institute, Babol 47|47-47745, Islamic Republic of Iran

Tel +989113158440

Email bakouei2004@yahoo.com
Purpose: Self-efficacy not only concentrates on specialty and competence but also considers the individual beliefs about what is obtainable. This study aimed to determine the effect of demographic and socioeconomic variables on self-efficacy status in students of Babol University of Medical Sciences.

Methods: This cross-sectional study was performed on 350 students of Babol University of Medical Sciences in 2016. The clustering-systematic random multi-stage sampling method was used for sampling. Data were collected using two demographic and socioeconomic status questionnaires as well as a General Self-Efficacy Scale (GSE). The collected data were analyzed using SPSS software version 18 at a significance level of $P \leq 0.05$.

Results: The mean age of students was $21.37 \pm 2.28$ years, and most participants were female (58\%). The highest number of students (65.7\%) studied at the bachelor level. The students' mean total self-efficacy score was $61.08 \pm 8.67$ and ranged between 25 and 82 . There was a significant statistical relationship between self-efficacy index and variables such as family income, school, and grade. The highest positive relationship was observed in proper family income and the mean grade was higher than $16(P \leq 0.001)$. Students in Rehabilitation and Paramedical Schools had lower self-efficacy compared to medical and paramedical students. Conclusion: Students' self-efficacy is dependent on various socioeconomic and educational factors such as family income, academic grade, academic year, and school; so recognizing these factors can play an important and effective role in improving students' academic achievement. Therefore, it is recommended to use effective educational interventions in colleges with students' active role in different fields in order to promote students' selfefficacy and improve their self-esteem and self-confidence.

Keywords: demographic variables, self-efficacy, students

\section{Introduction}

One of the critical periods in youth is during studying at university, which is known as a transitional and dynamic period. Within this period, young people gradually accept the responsibility of their health physically, mentally, socially, and sexually. This transitional period is the best time to develop healthy behaviors. ${ }^{1}$ Entrance to the university is accompanied by certain emotions that can affect the students' mental and physical health. ${ }^{2}$ A study on Egyptian students in 2007 showed that $86 \%$ of the students had an unhealthy diet and $25.3 \%$ were overweight; $33.8 \%$ had lack of physical activity and $17.5 \%$ were smokers. ${ }^{3}$ Therefore, students must be aware of the proper health behaviors in order to apply them for improving their 
health and quality of life. ${ }^{4}$ Students are a large part of our young population, and their age and social status, as a well-educated community, can make them a model role for others. So, their selection of any lifestyle not only affects their own personal lives but also affects the behaviors and lifestyles of other people. ${ }^{5}$ Based on a global scale, researchers have found that many students are involved in high-risk behaviors such as drinking alcohol, tobacco use, physical inactivity, and unhealthy diet. ${ }^{6}$ Bandura defines self-efficacy as the capacity perceived by an individual to successfully implement one's behavior. As a result, self-efficacy is a cognitive concept and compares behavioral needs with individual capacities. According to Bandura, these factors are effective in creating self-efficacy: 1) Successful experiences, 2) Succession experiences, 3) Verbal or social stimuli, and 4) Emotional and physiological conditions. ${ }^{7}$ Self-efficacy is one of the key structures in many educational and health promotion patterns, which means "a person's confidence to be successful in performing a behavior". ${ }^{8}$ Self-efficacy affects how to choose a behavior, and it is effective on behavioral changes $;{ }^{9}$ so it plays an important role in formulating effective methods for designing educational interventions and programs. ${ }^{10}$ In fact, self-efficacy shows the person's perception of his ability to utilize his cognitive, emotional, behavioral, and perceptual skills. It is an important concept in positive psychology, and it is also effective on individual's self-confidence and abilities to apply in sensitive and risky situations. ${ }^{11}$

More self-efficacy results in higher strength, resistance, and flexibility. People with high level of self-efficacy believe that they are able to effectively affect their life events and expect more success than those who had lower self-efficacy. ${ }^{12}$ It not only concentrates on specialty and competency but also focuses on individual beliefs about what is unobtainable. ${ }^{13}$ Soltani and Peyravi in a study aimed to determine perceived self-efficacy in students of medical, arts, engineering, and humanities in 2014 found that medical students had significantly higher level of selfefficacy than other students. There was no significant difference in the learning styles and self-efficacy between girls and boys. ${ }^{14}$ Adio (2010) conducted a descriptive study to determine the level of self-efficacy in 381 librarians and finding relationship among demographic characteristics (eg, age, gender, marital status, academic background, and occupation), self-efficacy and professional commitment of librarians in 24 libraries of the federal university of Nigeria, and they found a significant relationship between self-efficacy with professional commitment and the relationship between age, gender, marital status, and work experience with librarians' professional commitment. ${ }^{15}$ Mokhtari Pour et al (2007) performed a descriptive-analytic study entitled "The Relationship between Demographic Variables with Anxiety and Depression among Students of Isfahan University of Medical Sciences" on 200 students selected by random sampling and found that the variables of academic achievement and the field of study had a positive relationship with socioeconomic status and a negative relationship with anxiety. The researchers concluded that it would be beneficial to pay more attention to the mental health issues of this group of students in the country. ${ }^{16}$ Considering the importance of the concept of self-efficacy and the possibility to upgrade this efficiency by changing behavior, ${ }^{12}$ its current status among students can be identified and also its relation with health-promoting behaviors can be properly planned. Searching databases showed that there is a lack of studies conducted to analyze self-efficacy and the impact of demographic and socioeconomic variables on it. Therefore, this study aimed to determine the effect of demographic and socioeconomic variables on the self-efficacy status among the students of Babol University of Medical Sciences, so the results of this study could be used as the basic information in designing the necessary interventions and to improve the general health of students using the self-efficacy theory.

\section{Methods}

This cross-sectional study was performed on 350 Students of Babol University of Medical Sciences in 2016. The research population consisted of students from medical, dentistry, paramedical, and international schools. Based on the clustering-systematic random multi-stage sampling method, each school and then each field of study was considered as a classification and according to the number of students in each school and then each field of study, the subjects were selected using Systematic Random Sampling method. Based on the Morgan table, 350 cases were enough, and based on quota method the number of students divided by university schools included: 30 international branch students, 50 dentistry students, 120 paramedical students, and 150 medical students. The students were invited to participate in the study after explaining the main objectives of the study and giving advice on how to complete the questionnaires. All participants were assured about the complete confidentiality of their information. If a student was not willing to participate in the 
study, another person was replaced from that school. The inclusion criteria were: studying at one of the abovementioned schools and declaring the willingness to participate in the study. Those students with chronic illness, impairment, disability, and physical or psychological illness were excluded from the study. The students provided verbal informed consent to participate in this study, and this was acceptable and approved by the Research Council of the Babol University under code 9440416 . This study was also approved by the Research Council of the Babol University. In order to investigate the students' academic performance, the students' mean academic grade of the last two semesters was used based on an inquiry from the educational deputy. Two questionnaires were used to collect other data: a) Demographic characteristics and socioeconomic status questionnaire including age, gender, field of study, place of residence, marital status, and socioeconomic status of their family; b) General Self-efficacy Scale (GSE) questionnaire was used to examine the concept of self-efficiency; this tool was designed by Sherer and Madox in 1982 to measure selfefficacy. The main reason for using this questionnaire was the fact that it was specifically designed for students. The scores of this 17-item questionnaire were ranged by Likert scale from 1 (totally disagree) to 5 (totally agree). All questions scored 1 to 5 points, except questions 1, 3, 8, 9, 13, and 15 which were reciprocally scored. The lowest and highest total score of this questionnaire were 17 and 85 , respectively. The total score of the items in the questionnaire after recoding the negative items showed the degree of self-efficacy (recoding was performed after inserting data in the SPSS). So, the higher the score, the more the self-efficacy level. ${ }^{17}$ Validity and reliability of Persian version of this questionnaire have been confirmed in prior studies conducted in Iran with a minimum alpha Cronbach coefficient of $0.79 .{ }^{18}$ Reliability of this questionnaire in this study by alpha Cronbach coefficient was 0.84 . The obtained data were analyzed using SPSS software version 18. Considering the type of variables, the independent sample $t$-test, ANOVA and linear and multivariate regression tests were used; ANOVA test was used to evaluate multiple groups and $t$-test for binary groups of independent variables (demographic) in relation to dependent variable (self-efficacy). All calculations were performed at a significant level of $P \leq 0.05$.

\section{Results}

The mean age of participants was $21.37 \pm 2.28$ years, most of them were female (58\%), and $90 \%$ of the participants were single. The highest number of students $(65.7 \%)$ was from bachelor level, in which most of them included students in both medical and dentistry schools $34.3 \%$ (120 cases). The mean grade of last two semesters in the majority of participants (38.3\%) was less than 16 (Table 1).

The student's mean total self-efficacy score was $61.08 \pm 8.67$ and ranged between 25 and 82. As shown in Table 2, self-efficacy index had a statistically significant relationship with variables such as family income, school, academic grade, and academic year $(p \leq 0.05)$. According to findings, the self-efficiency level was higher in students whose family income was desirable, students in medical and dental schools, and students with academic grade higher than 16. Besides, female students had higher self-efficacy than male students, but this difference was not statistically significant. Also, there was no statistically significant relationship between self-efficacy and variables of marital status and birthplace (being native or non-native).

Table I Demographic and socioeconomic characteristics of the participants in the research

\begin{tabular}{|c|c|c|c|}
\hline \multicolumn{2}{|l|}{ Variable } & \multirow{4}{*}{$\begin{array}{l}\text { Frequency } \\
132 \\
204 \\
14\end{array}$} & \multirow{4}{*}{$\begin{array}{l}\text { Percent } \\
37.7 \\
58.3 \\
4\end{array}$} \\
\hline Age & $18-20$ years & & \\
\hline & $2 \mathrm{I}-25$ years & & \\
\hline & $26-30$ years & & \\
\hline \multirow[t]{2}{*}{ Sex } & Female & 203 & 58 \\
\hline & Male & 147 & 42 \\
\hline \multirow[t]{2}{*}{ Marital status } & Single & 315 & 90 \\
\hline & Married & 35 & 10 \\
\hline \multirow[t]{2}{*}{ Birthplace } & Native & 190 & 54.3 \\
\hline & Non-native & 159 & 45.4 \\
\hline \multirow[t]{3}{*}{ Family income } & Unfavorable & 25 & 7.1 \\
\hline & Medium & 104 & 29.7 \\
\hline & Favorable & 221 & 63.1 \\
\hline \multirow[t]{3}{*}{ Housing status } & With family & 132 & 38 \\
\hline & Dormitory & 194 & 55.9 \\
\hline & Rental & 21 & 6.1 \\
\hline \multirow[t]{3}{*}{ School } & Medical and Dentistry & 200 & 57.1 \\
\hline & Paramedical & 120 & 34.3 \\
\hline & Rehabilitation & 30 & 8.6 \\
\hline \multirow[t]{2}{*}{ Field of study } & Medical and Dentistry & 120 & 34.3 \\
\hline & $\begin{array}{l}\text { All Bachelor of states } \\
\text { (BSc.) }\end{array}$ & 230 & 65.7 \\
\hline Academic & Less than 16 & 134 & 38.3 \\
\hline average & 16 and more than 16 & 128 & 36.6 \\
\hline
\end{tabular}


Table 2 Relationship between demographic and socioeconomic variables with students' self-efficacy

\begin{tabular}{|c|c|c|c|}
\hline \multicolumn{2}{|l|}{ Variable } & \multirow{2}{*}{$\begin{array}{l}\text { Self-efficacy(M } \pm S D) \\
8.12 \pm 61.55 \\
9.67 \pm 60.44\end{array}$} & \multirow{2}{*}{\begin{tabular}{|l|}
$P$-value \\
0.238
\end{tabular}} \\
\hline Sex & $\begin{array}{l}\text { Female } \\
\text { Male }\end{array}$ & & \\
\hline Marital status & $\begin{array}{l}\text { Single } \\
\text { Married }\end{array}$ & $\begin{array}{l}9.51 \pm 60.11 \\
8.58 \pm 60.19\end{array}$ & 0.468 \\
\hline Birthplace & $\begin{array}{l}\text { Native } \\
\text { Non-native }\end{array}$ & $\begin{array}{l}9.06 \pm 60.47 \\
8.13 \pm 61.88\end{array}$ & 0.131 \\
\hline Family income & $\begin{array}{l}\text { Unfavorable } \\
\text { Medium } \\
\text { Favorable }\end{array}$ & $\begin{array}{l}10.44 \pm 55.24 \\
7.65 \pm 59.47 \\
8.53 \pm 62.51\end{array}$ & 0.001 \\
\hline Housing status & $\begin{array}{l}\text { With family } \\
\text { Dormitory } \\
\text { Rental }\end{array}$ & $\begin{array}{l}9.83 \pm 60.93 \\
8.21 \pm 61.04 \\
4.58 \pm 62.66\end{array}$ & 0.693 \\
\hline School & $\begin{array}{l}\text { Medical and Dentistry } \\
\text { Paramedical } \\
\text { Rehabilitation }\end{array}$ & $\begin{array}{l}8.87 \pm 62.01 \\
6.67 \pm 60.45 \\
10.59 \pm 57.43\end{array}$ & 0.016 \\
\hline Field of study & $\begin{array}{l}\text { Medical and Dentistry } \\
\text { All Bachelor of states(BSc.) }\end{array}$ & $\begin{array}{l}8.41 \pm 60.45 \\
9.07 \pm 62.31\end{array}$ & 0.057 \\
\hline Academic average & $\begin{array}{l}\text { Less than } 16 \\
16 \text { and more than } 16\end{array}$ & $\begin{array}{l}8.59 \pm 58.81 \\
7.35 \pm 62.59\end{array}$ & $P<0.001$ \\
\hline
\end{tabular}

Note: Significance level at $p \leq 0.05$ based on $t$-test and ANOVA tests.

In order to determine the factors affecting self-efficacy, the obtained scores were used as dependent variables in the multiple linear regression model. The variables of family income, school, academic year, and academic grade were used as independent variables. The highest positive relationship was observed in the family's desirable income and the academic grade above 16; so, the higher the family income, the more the self-efficacy level. Students in schools of rehabilitation and paramedics had lower self-efficacy level than medical and paramedical students (Table 3).

\section{Discussion}

This study was performed to investigate the relationship between some demographic and socioeconomic variables with self-efficacy status in students of Babol University of Medical Sciences. The results showed that self-efficacy status was moderate among these students and factors such as family income, school, and academic year had a significant relationship with self-efficacy. There have been studies performed in Iran and in the world on students' self-efficacy. For example, in line with the present study, Rostami et al's study in 2007 on 296 students showed that self-efficacy had a direct and meaningful relationship with family support. This research confirmed the role of academic environment in promoting self-efficacy. ${ }^{19}$ This can be based on the Bandura's ${ }^{20}$ theory, one of the factors increasing self-efficacy is receiving encouragement and endorsement from others. The study by Rezayat and Nayeri in 2013 indicated that the self-efficacy of nursing students had a significant relationship with family income. ${ }^{18}$ Similar to the findings of the present study, Jamali et al's research on 428 students of Bushehr University of Medical Sciences in 2013 showed that academic self-efficacy was an effective factor on academic success. ${ }^{21}$ Researchers also found that students with higher self-efficacy level had more academic achievements. ${ }^{22,23}$ These findings are consistent with the results of the present study. In line with the present study, there was no significant difference between the mean score of self-efficacy of male and female students. Saffari et $\mathrm{al}^{24}$ in 2012 studied the relationship between self-efficacy and academic achievement in students; Ajam ${ }^{25}$ in 2016 performed a study entitled "The prediction of academic self-efficacy through social health" and found a significant difference between the level of self-efficacy in male and female students. But in the study of Rafii et al in 2012, the gender was the only demographic variable which had a significant 
Table 3 Multivariate regression for the relationship between demographic variables and students' self-efficacy level

\begin{tabular}{|c|c|c|c|c|c|}
\hline \multicolumn{2}{|l|}{ Model } & Unstandardized coefficients B & SD & Standardized coefficients B & $P$-value \\
\hline \multicolumn{2}{|l|}{ Constant } & 53.37 & 2.41 & - & $P \leq 0.001$ \\
\hline School & $\begin{array}{l}\text { Medical and Dentistry } \\
\text { Paramedical } \\
\text { Rehabilitation }\end{array}$ & $\begin{array}{l}- \\
-2.167 \\
-4.324\end{array}$ & $\begin{array}{l}- \\
1.09 \\
1.70\end{array}$ & $\begin{array}{l}- \\
-1.28 \\
-1.58\end{array}$ & $\begin{array}{l}- \\
0.048 \\
0.012\end{array}$ \\
\hline Family income & $\begin{array}{l}\text { Unfavorable } \\
\text { Medium } \\
\text { Favorable }\end{array}$ & $\begin{array}{l}- \\
3 \\
4.82\end{array}$ & $\begin{array}{l}- \\
2.03 \\
1.94\end{array}$ & $\begin{array}{l}- \\
0.175 \\
0.289\end{array}$ & $\begin{array}{l}- \\
0.137 \\
0.014\end{array}$ \\
\hline Academic average & $\begin{array}{l}\text { Less than } 16 \\
16 \text { and more than } 16\end{array}$ & $\begin{array}{l}- \\
3.95\end{array}$ & $\begin{array}{l}- \\
1.011\end{array}$ & $\begin{array}{l}- \\
0.241\end{array}$ & $\begin{array}{l}- \\
P \leq 0.001\end{array}$ \\
\hline
\end{tabular}

Note: Based on the results, $13 \%$ of the self-efficacy dispersion values were explained by the variables in the model.

relationship with academic self-efficacy. ${ }^{26}$ Another research on the relationship between social anxiety and some of the demographic variables among nursing students in Tehran University of Medical Sciences, conducted by Ghezelbash et al in $2015,{ }^{27}$ showed that there was a significant relationship between school and social anxiety, but no meaningful relationship was found between social anxiety and gender, place of residence, and marital status, which was consistent with the findings of the present study. The most positive relationship was observed in the family's desirable income, which can be due to the fact that higher financial support from the family will give the student more confidence in doing their assignments. Torres et al (2006) also found a strong relationship between selfefficacy and family support among the students with English native language, ${ }^{28}$ which was in line with the present study. Students with a higher academic grade had also higher self-efficacy level. Self-efficacy is related to the ability and skills, and these students with higher academic grades feel more self-efficacious than their other classmates with lower academic grades. Therefore, it can be concluded that higher grades and higher self-efficacy have a positive and coherent cycle. That is, the higher the academic grade, the higher the self-efficacy level and vice versa, which is justified based on Bandura's self-efficacy theory. Bandura defines self-efficacy as one of the personal factors that can help a person to overcome obstacles in doing a specific behavior. Bandura believes that if a person has more successful experiences, he/she will be more confident about the ability to perform tasks. ${ }^{29}$ Consistent with the findings of the present study, the study of Chen et al (2009) ${ }^{30}$ on 120 English language students showed that students who were more self-efficacious had also better educational success and higher academic grades. Similar to the result of this study, Zajacova et al ${ }^{31}$ conducted a study in 2005 on 107 students at the University of New York and reported self-efficacy as a powerful predictor of academic achievement, which is consistent with the results of this study. The most negative relationship was observed in the Rehabilitation and the Paramedical schools; so, the students of these two schools had lower self-efficacy than the students of medical and dental schools. Therefore, the score of schools in terms of self-efficacy can be graded by 1) medical and dental schools, 2) Paramedical school, and 3) Rehabilitation school. In accordance with present study, Soltani et al (1394), in a descriptive-analytic study entitled "Comparison of learning styles and self-efficacy among medical, arts, engineering and human sciences students" on 100 male and female students, found that medical students had the highest levels of self-efficacy. ${ }^{14}$ Mohammadi et al performed a study on rehabilitation students (Physiotherapy, Speech Therapy, Occupational Therapy, Social Work) at Tehran University of Social Welfare and Rehabilitation Sciences in 2010 and found that the mean score of self-efficacy perception about clinical competence was moderate for students in all of these fields and need to be upgraded. ${ }^{32}$ It seems that the students of the two programs of medicine and dentistry who had higher rank in entrance examination and higher grade at high school had a sense of scientific excellence, more empowered and also stronger motivation than undergraduate students in two schools of rehabilitation and paramedics. This more positive attitude toward medical and dentistry students is also obvious in the community and even among university staff. One of the limitations of the present study was that the research population included 
merely from a medical university, so the results could not be generalized to all other universities. It is suggested to perform more studies at several academic levels. The second limitation included the sectional-descriptive method and using mental indices; it is recommended to other researchers to use empirical and objective criteria to examine the students' self-efficacy level. The third limitation of the study included the mental and psychological conditions of the participants while completing the questionnaires, which can affect the type of response, and, of course, has not been controlled by the researcher.

\section{Conclusion}

There are socioeconomic educational variables such as family income, academic grade, academic year, and school which have a significant relationship with students' selfefficacy level. These important results can play an important and effective role in qualitative and quantitative improvement in students' educational programs. Therefore, it is strongly recommended to use these variables for better planning and educational management especially social support, along with proper and complementary descriptive-analytic studies on. It is also necessary to provide educational interventions such as holding workshops and regular training sessions with the focus and active role of students in different fields in order to improve their self-efficacy and selfconfidence.

\section{Acknowledgments}

The authors would like to offer their special thanks to the Deputy of Student and Educational, Babol University of Medical Sciences, Babol, Iran. This manuscript was derived from a part of a research project done in Social Determinants of Health Research Center, Babol University of Medical Sciences. Special thanks to the Deputy of Research, Babol University of Medical Sciences and Social Determinants of Health Research Center, Babol University of Medical Sciences for their support.

\section{Disclosure}

The authors report no conflicts of interest in this work.

\section{References}

1. Motlagh Z, Mazloomy-Mahmoodabad SS, Momayyezi M. Study of health-promotion behaviors among university of medical sciences students. Zahedan. J. Res. Med. Sci. 2011;13(4):29-34. [In Persian].

2. Hosseini SH, Kazemi SH, Shahbaznezhad L. Evaluation of mental health in athletic and nonathletic students. J Mazandaran Univ Med Sci. 2006;16(53):97-104.
3. Abolfotouh M, Bassiouni F, Mounir G, Fayyad RC. Health-related lifestyles and risk behaviours among students living in Alexandria University hostels. East Mediterr Health J. 2007;3(2):376-91. doi:10.1094/PDIS-91-4-0467B

4. Shaban M, Mehran A, Taghlili F. Relationship between perception of health concept and health promoting behaviors: a comparative study among Tehran university medical and non-medical Students. J Hayat. 2007;13(3):27-36.

5. Nilsaz M, Tavassoli E, Mazaheri MSF, Khezli M, Ghazanfari Z. Study of health-promoting behaviors and life style among students of Dezful universities. Sci J Ilam Univ Med Sci. 2012;20(5):168-175.

6. Von Ah D, Ebert S, Ngamvitroj A, Park N, DH K. Predictors of health behaviours in college students. J Adv Nurs. 2004;48(5):463474. doi:10.1111/j.1365-2648.2004.03229.x

7. Taghdisi MH, Latifi M, Afkari ME, Dastoorpour M, Estebsari F, Jamalzadeh $\mathrm{F}$. The impact of educational intervention to increase self efficacy and awareness for the prevention of domestic violence against women. Iran J Health Educ Health Promotion. 2015;3(1):32-38.

8. Araban M, Tavvafian SS, Motesaddi Zarandi SHA, Gohari MR, Laloie A, Montazeri A. Effectiveness of a motivational interviewing session to enhance self-efficacy of pregnant women in response to air pollution preventive behaviors: a randomized trial. J Iran Inst Health SCi PAYESH. 2014;13(1):83-90.

9. Bandura A. Self-efficacy: toward a unifying theory of behavioral change. Psychol Rev. 1977;84(2):191-215.

10. Zulkosky K. Self-efficacy: a concept analysis. Nursing Forum 2009;44:93-102. doi:10.1111/j.1744-6198.2009.00132.x

11. Jamshidimanesh M, Alimanesh N, Behbodi Moghaddam Z, Haghani $\mathrm{H}$. Effect of an educational package on self-efficacy of infertile women. J Iran Inst Health Sci Res PAYESH. 2015;2:227-237.

12. Solhi M, Kazemi SS, Haghni H. Relationship between general health and self-efficacy in women referred to health center No. 2 in Chaloos (2012). Razi J Med Sci. 2013;20(109):63-70.

13. Bong M, Skaalvik EM. Academic self-concept and self-efficacy: how different are they really? Educ Psychol Rev. 2003;15(1):1-40. doi:10.1023/A:1021302408382

14. Soltani N, Peyravi A. The comparison between learning styles and self-efficacy of students of Medical Sciences, Art, Engineering, and Human Sciences. Paramedical Sci Mil Health. 2015;10(2):35-41.

15. Adio G, Popoola S. Demographic variables and self-efficacy as factors influencing career commitment of librarians in Federal University libraries in Nigeria. Lib Philoso Pract. 2010;329:1-9.

16. Mokhtaripour M, Goodarzi Z, Siadat A, Keivanara M. Anxiety, depression and some of their demographic correlates in students of Isfahan Medical University. J Res Behav Sci. 2007;5(2):107-112.

17. Sherer M, Maddux JE, Mercandante B, Prentice-Dunn S, Jacobs B, Rogers RW. The self-efficacy scale: construction and validation. Psychol Rep. 1982;51(2):663-671. doi:10.2466/ pr0.1982.51.2.663

18. Rezayat F, Nayeri ND. Self-efficacy after life skills training: a casecontrol study. Nurs Midwifery Stud. 2013;2(4):83-88.

19. Rostami R, Shahmohamadi K, Ghaedi G, Besharat MA, Akbari Zardkhaneh S, Nosratabadi M. Relations among self-efficacy, emotional intelligence and perceived social support in university students. Horizon Med Sci. 2010;16(3):46-54.

20. Albert B. Self-efficacy: toward a unifying theory of behavioral change. Psych Review 1997;84(2):191-215. doi:10.1037/0033295X842.191.

21. Jamali M, Noroozi A, Tahmasebi R. Factors affecting academic selfefficacy and its association with academic achievment among students of Bushehr University Medical Sciences 2012-13. Iran J Med Educ. 2013;13(8):629-641.

22. Tenaw YA. Relationship between self-efficacy, academic achievement and gender in analytical chemistry at Debre Markos College of teacher education. Afr J Chem Educ. 2013;3(1):3-28. 
23. Tella A, Tella A, Adeniyi SO. Locus of control, interest in schooling and self-efficacy as predictors of academic achievement among Junior Secondary School Students in Osun State, Nigeria. New Horiz Educ. 2011;59(1):25-37.

24. Saffari M, Sanaeinasab H, Rshidi Jahan H, Purtaghi GhH HPA. Happiness, self-efficacy and academic achievement among students of Baqiyatallah University of Medical Sciences. J Med Educ Dev. 2014;7 (13):22-29.

25. Ajam AA. The prediction of academic self-efficacy through social well-being of students at University of Medical Sciences. EDCBMJ. 2016;9(1):71-78.

26. Rafii F, Sarami Rasouli F, Najafi Ghezeljeh T, Haghani H. The relationship between academic procrastination, academic achievement, and self-efficacy in nursing students of Tehran University of Medical Sciences. Iran J Med Educ. 2014;14(1):32-40.

27. Ghezelbash S, Peyrovi H, Inanloo M, Haghani H. Relationship between social anxiety and some demographic characteristics among nursing students. J Healthc. 2015;17(1):19-29.
28. Torres JB, Solberg VS. Role of self-efficacy, stress, social integration, and family support in Latino college student persistence and health. $J$ Vocat Behav. 2001;59(1):53-63. doi:10.1006/jvbe.2000.1785

29. Saffari M, Shojaeizadeh D, Ghofranipour F, Heydarnia A, Pakpour A. Health education \& promotion-theories, models \& methods. Tehran Sobhan Pub. 2009;21-12.

30. Chen M, Lin H-J. Self-efficacy, foreign language anxiety as predictors of academic performance among professional program students in a general English proficiency writing test. Percept Mot Skills. 2009;109(2):420-430. doi:10.2466/PMS.109.2.420-430

31. Zajacova A, Lynch SM, Espenshade TJ. Self-efficacy, stress, and academic success in college. Res High Educ. 2005;46(6):677-706. doi:10.1007/s11162-004-4139-z

32. Mohammadi F, Hosseini MA. Rehabilitation sciences students' perception from clinical self-efficacy compared to evaluation by clinical teachers. Iran J Med Educ. 2010;10(2):155-163.

\section{Publish your work in this journal}

Advances in Medical Education and Practice is an international, peerreviewed, open access journal that aims to present and publish research on Medical Education covering medical, dental, nursing and allied health care professional education. The journal covers undergraduate education, postgraduate training and continuing medical education including emerging trends and innovative models linking education, research, and health care services. The manuscript management system is completely online and includes a very quick and fair peer-review system. Visit http://www.dovepress.com/testimonials.php to read real quotes from published authors. 